\title{
A contribuição do diagnóstico para traçar a estratégia da empresa - Estudo de caso de uma empresa de confecção
}

\section{The contribution of diagnosis to trace the company's strategy - A clothing firm case study}

\section{DALBETO, Lucas do Carmo I Pós-graduando em Gestão de Design}

Universidade Estadual de Londrina I UEL

Icdalbeto@yahoo.com.br

\section{GONC̣ALVES, Mayara I Pós-graduanda em Gestão de Design}

Universidade Estadual de Londrina I UEL

maygoncalvess@hotmail.com

\begin{abstract}
Resumo
O presente artigo resgata o conceito de design em suas diferentes aplicações esclarecendo as relações entre doutrinas e práticas da atuação dos designers, relacionando a fatores gerenciais e ao desempenho e contribuições da Gestão do Design dentro das organizações. Como auxílio da exemplificação das atividades de gestores de design, utiliza-se do diagnóstico como um método de verificação da situação atual de uma empresa de confecção, com o objetivo de obter informações necessárias para realização de planejamentos e estratégias que devem ser aplicadas através de ações de Gestão de Design visando valorizar e beneficiar

\section{Abstract}

This paper demonstrates the concept of design in its differents means, clarifying the relationship between doctrine and practice of the performance of designers, and relating to management and performance and contributions os the Design Management for the organizations. To illustrate the activities of design managers, the diagnostic is used as a method of verifying the current status of a clothing firm, in order to obtain the necessary information to develop plans and strategies to be implemented through actions of management design in order to value and benefit the company on the market.
\end{abstract} à empresa diante do mercado.

Palavras Chave: Gestão de Design. Keywords: Design Management. Diagnostic. Diagnóstico. Competitividade.

Competitiveness. 


\section{INTRODUCÃO}

Nos últimos anos as indústrias transpõem sucessivos processos de modernização provocados pelo constante crescimento da concorrência, que em decorrência da globalização, provoca competições entre pequenas empresas e multinacionais e se reflete no aumento de produtos oferecidos aos consumidores, diferenciados por inúmeras características, acarretando suscetíveis mudanças de costumes e cotidiano das pessoas.

É comum que problemas sejam detectados nas empresas, principalmente em empresas que estão relacionadas a processos de produção de produtos e interligadas a criação, como é o caso da empresa de confecção utilizada como objeto de análise deste artigo, que será tratada por Empresa B. Diante desta realidade é notória a necessidade de identificar problemas e dificuldades e a urgência em realizar mudanças que possam adicionar atributos e reforçar a marca ao mercado, a fim de valorizar seus produtos perante concorrentes.

Nesse âmbito de transformações, de tornar a empresa competitiva, o Manual de Gestão de Design (1997, p. 61) retrata o design como chave para a incorporação de novas estratégias, um processo a ser gerenciado, já que o mesmo trabalha de forma multidisciplinar, planificando e lançando novos produtos no mercado.

Em prol de soluções e acertos na inserção de seus produtos no mercado de forma a tornar a empresa competitiva e corresponder às expectativas dos consumidores, transformações e adaptações inovadoras devem ser realizadas dentro da empresa. Assim, a Gestão do Design diretamente ligado ao Design Estratégico torna-se um instrumento para consolidação de tais desejos, apresentando resultados em longo e médio prazo.

Diante a esse contexto o presente trabalho objetiva abordar a atuação do design dentro das organizações, bem como a relevância de inserir a Gestão de Design como plano estratégico e de diferenciação mercadológica, abordando seus conceitos para melhor compreensão. Nesta pesquisa utiliza-se a ferramenta de diagnóstico para identificar e apontar os problemas e os aspectos relevantes que envolvem a empresa avaliada (Empresa B). O diagnóstico foi realizado através de uma entrevista com roteiro semi-estruturado com a proprietária, apresentando questões que abordavam as 10 dimensões propostas pelo Manual de Gestão de Design (1997). O diagnóstico permitiu visualizar com clareza o cenário em que a empresa se encontra e a possibilidade de traçar planos estratégicos e mudanças a fim de atingir um estado melhor e mais desejável do que o atual, trabalhar os aspectos "chaves" e as pretensões e necessidades com base na sua realizadade, sejam elas imediatas ou de longo prazo. 


\section{A COMPLEXIDADE DA ATIVIDADE DE DESIGN}

Existem diversas definições de design. Erlhoff e Marshall (2008, apud ODA, 2010) explicam que a palavra deriva do latim designare, que traduzida significa definir, desenhar, em alemão design é criação da forma, e em inglês a palavra pode assumir diversas significações de acordo com o contexto. $\mathrm{Na}$ frase de Heskett (1989, apud MAGALHÃES, 1997, p. 17), "Design is when designers design a design for the production of a design", que em tradução livre seria "Design é quando designers projetam um design para a produção de um design", pode-se notar os diversos aspectos tomados pelo termo design em que, de certa forma, um todo passa a se confundir com suas partes (MAGALHÃES, 1997).

Ao primeiro "design" da frase será tomando o significado projetar, desenvolver. No Brasil estas nomenclaturas passaram a ser adotadas quando nos referimos ao processo de design, que não é apenas uma espécie de processo mental, e sim uma combinação de metodologias e meios utilizados pelo design. Segundo Medeiros (1981, apud MAGALHÃES, 1997) a metodologia está diretamente ligado ao projeto e envolve dois aspectos fundamentais: o primeiro foca o planejamento e a programação do projeto, que determinam as atividades que auxiliaram a controlá-lo; e o segundo aspecto refere-se à atuação na concepção do produto (resultado) propriamente dito, que irá envolver os processos criativos, métodos e técnicas de desenvolvimento do produto, em que se elaboram modelos ou então se adota algum dos disponíveis na literatura.

Para os profissionais de design, criar significa que há um problema que primeiro precisa ser identificado pra então ser resolvido. Uma vez identificado o problema, o designer segue um processo lógico, que ele aplica a cada fase do projeto. Esse processo é uma habilidade aprendida que corresponde a técnicas, e não um talento misteriosamente inerente a alguém. O processo é o mesmo caso a empresa opte por trabalhar com uma agência externa ou por desenvolver ela própria um setor de design (MOZOTA, 2011, p. 27).

O segundo design da frase se refere à configuração que o produto adquire através da intervenção do designer, que é capaz de empregar as funções simbólicas, estéticas e funcionais do produto por meio de estudos aprofundados e de seus conhecimentos vinculados a sua experiência profissional. Design é o resultado do projeto. Esta abordagem contribui para a ação do nível operacional do design, quando se trata de estratégias diretamente ligadas ao processo de design estas abordagens podem ser classificadas como "Design para a racionalização" e "Design para a diferenciação". 
O último termo design da frase corresponde ao produto propriamente dito, porém considerar o resultado de design apenas como o produto final, seja ela proveniente do processo de design gráfico ou de produto, é uma definição bastante simplória. O desenvolvimento de produtos se baseia, principalmente, nos aspectos cognitivos do usuário e suas necessidades. Logo o designer deve conhecer as necessidades que possui o mercado alvo, além de entender como seu público irá perceber e avaliar os benefícios empregados em seu trabalho.

O design, de acordo com Magalhães (1997), é um meio para a satisfação do usuário, desta forma o mais importante aspecto proveniente dele é a sensação despertada no usuário. Segundo o autor (ibidem) o produto é apenas a interface utilizada pelos designers e usuários para atingir as demandas sensoriais. Desta forma é importante que o designer não esteja apenas vinculado ao processo de desenvolvimento de produtos de uma organização, mas sim estar inserido em sua estratégia. Quanto mais inserido na estratégia da empresa estes profissionais estiverem, a mais informações eles terão acesso para poder desenvolver produtos competitivos que sejam mais atrativos aos consumidores, que buscam o melhor valor percebido.

O International Council of Societies of Industrial Design (ICSID) conceitua o design como uma atividade que não está restrita apenas ao ambiente empresarial, mas também se refere a parte central da inovação e das mudanças culturais e econômicas (ODA, 2010).

É indiscutível o papel que o design vem exercendo como agregador de valor aos produtos no atual momento econômico. Inicialmente produtos e serviços disponíveis no mercado eram aceitos mesmo sem grandes inovações ou diferenciações, porém este cenário vem se alterando consideravelmente, e o consumidor que era considerado passivo passa a ter um importante papel como o protagonista do mercado (FUJITA; BECKER; KISTMANN, 2010). Bahiana (1998, apud NETO; TEIXEIRA; MERINO, 2009) ressalta a importância que o design vem adquirindo como questão estratégica e não mais apenas como uma questão de atributos estéticos e de qualidades subjetivas. As empresas que adotaram técnicas de gestão de design sobressaíram-se às demais através da diferenciação de seus produtos e da racionalização dos custos de produção.

Conforme a definição do ICSID uma das diversas funções das atividades do design é a tradução de inovação em produtos e serviços realizada de maneira contínua pela organização, no entanto a atuação do design extrapola os processos de desenvolvimento e produção e passa a buscar sistematização e controle nos processos de gestão (RODA; KRUCKEN, 2004). Compreendido a abrangência do design Oda (2010) ressalta a necessidade de uma metodologia e de mecanismos de controle para a gestão do design, que possam garantir que 
o design atenda os padrões de qualidade e inovação necessários.

Este novo enfoque, de acordo com o Manual de Gestão de Design (1997, p. 23), emerge como uma atividade "aberta a todos os profissionais que se ocupam dos produtos, designers industriais, especialistas em marketing, engenheiros", mas exigirá uma nova perspectiva para atender às necessidades de gestão da empresa e "reconhecer a importância do design de produto e da comunicação como variáveis decisivas da eficácia empresarial".

Martins \& Merino (2008) definem que o que difere a Gestão de Design das demais atividades gestoras é a capacidade de identificar e comunicar as formas pelas quais o design pode contribuir para o valor estratégico da empresa, ou seja, desdobrar a atividade do design na empresa de modo que ele possa contribuir para a construção da estratégia organizacional.

A Gestão de Design, segundo Mozota (2002 apud MARTINS; MERINO, 2008) está relacionada às mudanças dos processos administrativos do modelo taylorista, hierárquico, para um modelo mais informal, fundamentado em conceitos relacionados ao design, como gestão orientada ao cliente, baseada em projetos e gestão da qualidade total. A mudança destes processos gerou uma demanda por uma gestão interna do design (MOZOTA, 2011), para que este deixasse de ser um processo para concretizar um negócio ou estratégia de marketing e fosse capaz de contribuir para a mudança de comportamento e da visão corporativa.

Mozota (2002, apud MARTINS; MERINO, 2008, p. 144) caracteriza a Gestão de Design como uma atividade a fim de "explicar o Design aos gerentes e, reciprocamente, o gerenciamento aos designers, a fim de ajudá-los a melhor gerenciar suas atividades e definir os métodos de gestão para integrar o Design na empresa", e pode ser adotada em dois níveis.

\begin{abstract}
A gestão do design, estratégica e operacional, tem como principais funcões: a definição dos objetivos e valores da empresa (missão), incluindo os objetivos do design; o desenvolvimento de uma estratégia baseada na missão; a execução e organização da estratégia; a coordenação e controle do processo de produção e o controle do resultado (CÂMARA et al., 2007, p. 4).
\end{abstract}

A gestão no nível operacional é uma ferramenta para integrar as funções operacionais de design desenvolvidas nos setores da organização, visando atingir os objetivos estabelecidos e proporcionar uma boa imagem percebida (CÂMARA et al., 2007). Oda (2010) caracteriza o design no nível operacional 
como a manifestação física e tangível nos produtos.

No nível estratégico requer o compartilhamento de recursos humanos e implementação da cultura de projeto coletivo na organização (Monteiro, 2003, apud CÂMARA et al., 2007). O Manual de Gestão de Design (1997, p. 24) cita como principais aspectos deste nível:

- O diagnóstico da situação da empresa e as possibilidades tecnológicas em relação aos seus concorrentes;

- Definição do futuro da organização;

- Determinação das opções em relação aos pontos positivos e negativos da organização;

- Integração entre as diversas áreas da organização (marketing, produção, engenharia, design, etc.) a fim de determinar as oportunidades e riscos;

- Estabelecer design e inovação como algo inerente a cultura organizacional como aspectos necessários para obter rentabilidade a longo prazo.

Neste nível as organizações não competem através da eficácia de produção, da administração financeira ou nos sistema de logística, mas sim através de seus produtos, serviços e da qualidade que pode oferecer a seus clientes e consumidores (MANUAL DE GESTÃO DE DESIGN, 1997, p. 25).

O quadro abaixo desenvolvido por Magalhães e adaptado por Martins \& Merino (2008) apresenta uma comparação entre os dois níveis.

Quadro 1 - Quadro comparativo entre design operacional e design estratégico.

\begin{tabular}{|l|l|}
\hline DESIGN OPERACIONAL & DESIGN ESTRATÉGICO \\
\hline $\begin{array}{l}\text { Ação a partir de uma proposta inicial } \\
\text { dada }\end{array}$ & $\begin{array}{l}\text { Ação desde proposta do projeto, } \\
\text { concepção e demais etapas envolvidas } \\
\text { no processo. }\end{array}$ \\
\hline Ação isolada, habilitação específica. & $\begin{array}{l}\text { Ação catalisadora de conhecimentos } \\
\text { envolvidos no processo, integração. }\end{array}$ \\
\hline Pensamento fracionado. & Pensamento global. \\
\hline Eficiência do design. & Eficiência + eficiência do Design. \\
\hline Desenvolver corretamente o produto. & Desenvolver o produto certo. \\
\hline
\end{tabular}




\begin{tabular}{|l|l|}
\hline $\begin{array}{l}\text { Ênfase nas necessidades do usuário do } \\
\text { produto. }\end{array}$ & $\begin{array}{l}\text { Enfase nas necessidades, desejos } \\
\text { e conveniências do beneficiário do } \\
\text { produto (incluindo cliente, consumidor, } \\
\text { usuário, fabricante, fornecedor e } \\
\text { sociedade). } \\
\text { Concorrência como referência. }\end{array}$ \\
\hline Ênfase na solução de problemas. & $\begin{array}{l}\text { Monitoramento dos problemas e } \\
\text { prospecção das oportunidades. }\end{array}$ \\
\hline $\begin{array}{l}\text { Processo de dentro para fora do produto } \\
\text { - a forma segue a função. }\end{array}$ & $\begin{array}{l}\text { Processo de fora para dentro do produto } \\
\text { - a forma segue a mensagem (o que o } \\
\text { público percebe). }\end{array}$ \\
\hline $\begin{array}{l}\text { Solução dos problemas físicos do } \\
\text { produto. }\end{array}$ & \begin{tabular}{l} 
Posicionamento emocional do produto. \\
\hline
\end{tabular}
\end{tabular}

Fonte: Martins e Merino (2008, p. 160). (Adaptado de MAGALHÃES, 1997).

Segundo os autores, apesar de não ser o que acontece na prática, é importante ressaltar que o nível operacional não está em um nível

abaixo do nível estratégico. Tanto a Gestão estratégica, quanto a Gestão operacional tem como objetivo "definir os objetivos e valores da empresa (missão), incluindo os objetivos do Design; o desenvolvimento de uma estratégia baseada na missão; a execução e organização da estratégia; a coordenação e controle do processo de produção e controle do resultado" (MARTINS; MERINO, 2008, p. 160).

Oda (2010) cita ainda um 3ำ nível de Gestão proposto por Mozota, o nível funcional, no qual o design atua como coordenador ou integrador com outras áreas da corporação, como marketing, inovação e comunicação. Neste nível, segundo a autora, a gestão de design intermedia as estratégias da empresa e as ações de design.

Quadro 2 - Os 3 níveis da Gestão de Design segundo Mozota

\begin{tabular}{|l|l|l|}
\hline DESIGN AC̣ÃO & DESIGN FUNC̣ÃO & DESIGN VISÃO \\
\hline $\begin{array}{l}\text { Valor diferenciador do } \\
\text { design }\end{array}$ & $\begin{array}{l}\text { Valor coordenador do } \\
\text { design }\end{array}$ & $\begin{array}{l}\text { Valor transformador do } \\
\text { design }\end{array}$ \\
\hline
\end{tabular}




\begin{tabular}{|l|l|l|}
\hline $\begin{array}{l}\text { O design é uma } \\
\text { competência econômica } \\
\text { que atua nas atividades } \\
\text { primárias da cadeia de } \\
\text { valor }\end{array}$ & $\begin{array}{l}\text { O design é uma } \\
\text { competência gerencial } \\
\text { que atua nas atividades de } \\
\text { suporte da cadeia de valor }\end{array}$ & $\begin{array}{l}\text { O design é uma } \\
\text { competência central que } \\
\text { atua na cadeia de valor do } \\
\text { setor e da visão da } \\
\text { indústria }\end{array}$ \\
\hline $\begin{array}{l}\text { Brand Marketing } \\
\text { Produção } \\
\text { Comunicação }\end{array}$ & $\begin{array}{l}\text { Estrutura } \\
\text { Gestão da tecnologia } \\
\text { Gestão da Inovação }\end{array}$ & $\begin{array}{l}\text { Estratégia } \\
\text { Gestão do conhecimento } \\
\text { Gestão do relacionamento }\end{array}$ \\
\hline $\begin{array}{l}\text { Gestão de Design } \\
\text { Operacional }\end{array}$ & $\begin{array}{l}\text { Gestão de Design } \\
\text { Funcional }\end{array}$ & $\begin{array}{l}\text { Gestão de Design } \\
\text { Estratégico }\end{array}$ \\
\hline
\end{tabular}

Fonte: Oda (2010, p. 25) (Adaptado)

Desta forma a Gestão de Design pode então ser entendida como o "gerenciamento da atividade de design alinhada aos objetivos da empresa e integrada com outras áreas, visando o alcance da estratégia empresarial e contribuindo para sua competitividade" (ODA, 2010, p. 26).

\section{DESIGN COMO ESTRATÉGIA COMPETITIVA}

Para Mozota (2011, p. 180) "estratégia competitiva tem a ver com ser diferente. Significa escolher deliberadamente um conjunto diverso de atividades para oferecer uma combinação única de valor". Contudo, a estratégia não depende unicamente do gerenciamento em design, mas da realização das atividades de maneira integrada e bem sucedida por meio de todos os setores e funcionários.

Em meio a esse contexto, Camilo Belchior (2010) expõe a seguinte interpretação:

O designer estratégico trabalha analisando a situação de mercado e da empresa, criando um diagnóstico funcional, cujo objetivo é detectar, na empresa ou produto, dados conceituais e estruturas simbólicas que possam representar a marca. Ele ainda avalia os objetivos dos envolvidos, empresa ou consumidor, a fim de encontrar todas as informações que podem ser usadas na gestão estratégicas da empresa [...], procurando integrar as várias áreas diante do objetivo global (BELCHIOR, 2010).

É fato que o objetivo das organizações com fins lucrativos é obter o maior 
retorno possível sobre o investimento, dentro do menor prazo, em outras palavras, as organizações buscam a competitividade no mercado. Prahalad e Ramaswamy (2004, apud COSTA, 2010, p. 10) afirmam que a globalização modificou o panorama competitivo de mercado, e nesta nova realidade inovação e criatividade são fortes diferenciais para aumento do lucro, no entanto, como afirmam Coutinho e Ferraz (1994, apud RECH, 2006), o comportamento competitivo é dependente de diversos fatores, dentre eles os fatores empresariais, internos à empresa, os fatores estruturais, que correspondem aos fatores inerentes aos setores, e os fatores de natureza sistêmica, sobre os quais o poder de intervenção é praticamente nulo.

Fujita, Becker e Kistmann (2010) diferencia a vantagem competitiva de acordo com as teorias de estratégia empresarial tomando o ambiente externo como o elemento mais importante para a determinação estratégica (cadeia de valor de Porter), ou o ambiente interno da organização (visão baseada em recursos - VBR). Conforme Mozota (2011) ressalta, a formulação da estratégia da empresa contempla tanto a análise de variáveis externas quanto a de variáveis internas, porém para que uma empresa se mantenha em uma posição privilegiada de vantagem competitiva no mercado estas variáveis devem ser frequentemente acompanhadas. Uma importante ferramenta para o fornecimento destas informações é o diagnóstico estratégico (ODA, 2010; TERENCE; ESCRIVAO FILHO, 2007; SILVA, 2009; MACRI; MARTINS, 2010), abordado a seguir.

\section{Diagnóstico}

Para compreensão do conceito de diagnóstico estratégico, Oliveira (2005, apud ODA, 2010) retrata como uma avaliação ou método de dimensionamento do estado presente de uma empresa com a finalidade de definir condições necessárias para atingir um novo estado, mais desejável do que o presente. $\mathrm{O}$ autor acrescenta que não existe um único diagnóstico, pois o mesmo é definido pelo resultado do conjunto de variáveis estudadas, e da profundidade que são analisadas, desde o contexto histórico até o momento da execução.

Oliveira (2006, apud LOPES et al., 2008) define o diagnóstico estratégico como um processo interativo a ser realizado por um profissional de fora da organização, contratado para auxiliar na tomada de decisões. O quadro abaixo expõe os quatro passos básicos, segundo o autor, necessários para a realização de um diagnóstico estratégico. 
Quadro 3 - Passos básicos para a realização de um diagnóstico estratégico segundo Oliveira

\begin{tabular}{|l|l|}
\hline $\begin{array}{l}\text { Formulação da hipótese } \\
\text { de problema }\end{array}$ & $\begin{array}{l}\text { Identificação das forças desestabilizadoras - internas } \\
\text { ou externas - que possam gerar problemas para a } \\
\text { organização. São formulados através de hipóteses, } \\
\text { uma vez que a identificação destes será resultante do } \\
\text { próprio diagnóstico. }\end{array}$ \\
\hline $\begin{array}{l}\text { Coleta de informações } \\
\text { a respeito do possível } \\
\text { problema }\end{array}$ & $\begin{array}{l}\text { A obtenção das informaç̃̃es está relacionada ao tipo } \\
\text { de diagnóstico que se pretende realizar. O custo desta } \\
\text { pesquisa deve ser proporcional à valorização desta } \\
\text { para o conhecimento do problema. }\end{array}$ \\
\hline Analisar a informação & $\begin{array}{l}\text { Esta etapa compreende a capacidade de análise da } \\
\text { equipe de diagnóstico para a melhor identificação } \\
\text { e definição do problema. Implica em comparar as } \\
\text { informações obtidas com o diagnóstico e com outras } \\
\text { situações similares ou ideais. }\end{array}$ \\
\hline $\begin{array}{l}\text { Realização do } \\
\text { Diagnóstico } \\
\text { Organizacional }\end{array}$ & $\begin{array}{l}\text { Tomada de decisões em relação aos resultados } \\
\text { obtidos. O diagnóstico pode ou não confirmar as } \\
\text { hipóteses do problema, em caso negativo novas } \\
\text { hipóteses devem ser elaboradas e o modelo deve ser } \\
\text { repetido. }\end{array}$ \\
\hline
\end{tabular}

Fonte: Os autores, adaptado de Lopes et al. (2008)..

O autor ressalta que, para que a análise seja efetiva, é necessário considerar o ambiente e as possíveis variáveis que possam atingir a organização. Segundo ele "ter o conhecimento desses fatores possibilita explorar as oportunidades e evitar as ameaças, ter pleno conhecimento de seus pontos fortes e fracos para saber posicionar-se no mercado e o processo de análise deve ser integrado, contínuo e acumulativo" (OLIVEIRA, 2006, apud LOPES et al., 2008, p. 10). As etapas do diagnóstico estratégico são compostas de elementos como: contexto histórico; missão, visão e valores corporativos; definição do público-alvo; posicionamento da empresa; e análise SWOT. Todos esses componentes são avaliados, possibilitando planejamento de estratégias futuras e acompanhamento das correções ao longo do tempo.

Conforme visto acima o diagnóstico é uma importante ferramenta capaz de fornecer informações para traçar a estratégia da empresa. A fim de conhecer a cultura organizacional e dimensionar a atual circunstância que a Empresa $B$ se encontra dentro da esfera interna e externa, foi realizado um diagnóstico por etapas, possibilitando a construção de um planejamento com a implantação de 
decisões e correções concisas, objetivando resultados futuros positivos.

\section{METODOLOGIA}

Para o diagnóstico foi realizada uma pesquisa de caráter qualitativo e exploratório, com roteiro semi-estruturado, com a direção da empresa e a equipe de desenvolvimento da marca.

Segundo Neves (1996) a pesquisa qualitativa é uma abordagem que vem ganhando grande espaço em áreas como a administração, a psicologia e a educação. Godoy (1995, apud DELGADO, 2007) enfatiza que a adoção da perspectiva qualitativa permite que determinado fenômeno possa ser compreendido melhor no próprio contexto em que ocorre, sendo assim o pesquisador vai a campo buscando "captar" o fenômeno em estudos a partir da perspectiva das pessoas nele envolvidas. Retomando Neves os estudos qualitativos devem ser feitos no local de origem dos dados, não impedem que o pesquisador empregue empirismo científico em fenômenos claramente definidos, porém partem da suposição de que "fenômenos singulares e dotados de certo grau de ambiguidade" devem ser analisados a partir da perspectiva fenomenológica.

O roteiro da entrevista foi adaptado do proposto pelo Manual de Gestão de Design (1997, p. 42) em que as 10 dimensões seguintes devem ser abordadas:

- Cultura de empresa e relação com seu meio ambiente;

- Estilo de gestão e sensibilidade dos dirigentes;

- Responsabilidades e estruturas criadas para desenvolvimento de produtos;

- Fator humano ou analise da capacidade e motivação individual para a criação de novos produtos;

- Meios e recursos dedicados ao empreendimento;

- Processo seguido para o DNP. Organização e procedimentos;

- Processo seguido para melhorar os atuais produtos. Organização e procedimentos;

- Gestão do projeto de design;

- Gestão de qualidade;

- Gestão de Inovação.

Nota-se que as 2 primeiras dimensões se referem à gestão estratégica de design, as 5 seguinte à gestão tática ou do processo de design e as 3 últimas dimensões abordam à gestão operacional de design, destacando que todas atuam de forma integrada, apesar de suas característica e ações serem distintas. 
A fim de conhecer a cultura organizacional e dimensionar a atual circunstância que a Empresa B se encontra dentro da esfera interna e externa, foi realizado um diagnóstico organizacional por etapas, possibilitando a construção de um planejamento com a implantação de decisões e correções concisas, objetivando resultados futuros positivos. Para a realização do diagnóstico considerou-se as abordagens apresentadas no quadro a seguir:

Quadro 4 - Abordagens utilizadas durante o processo de diagnóstico da Empresa B.

\begin{tabular}{|l|l|}
\hline Diagnóstico estratégico & $\begin{array}{l}\text { Visão da empresa, pontos fortes e fracos, ameaças e } \\
\text { oportunidades, cultura da empresa e relação com o } \\
\text { seu meio ambiente, estilo de gestão e sensibilidade dos } \\
\text { dirigentes. }\end{array}$ \\
\hline Diagnóstico tático & $\begin{array}{l}\text { Responsabilidades e estruturas criadas para o } \\
\text { desenvolvimento de produtos, análise da capacidade e } \\
\text { motivação individual para a criação de novos produtos, } \\
\text { meios e recursos dedicados ao empreendimento, } \\
\text { processo seguido para o desenvolvimento de novos } \\
\text { produtos, organização e procedimentos, gestão de } \\
\text { processos de design. }\end{array}$ \\
\hline Diagnóstico operacional & $\begin{array}{l}\text { Metodologia de design, análise do mapeamento do } \\
\text { processo de design, definição dos pontos críticos. }\end{array}$ \\
\hline
\end{tabular}

Fonte: Os autores.

Com base em tais conceitos, foi realizada uma visita preliminar a empresa com o objetivo de extrair as informações necessárias para construir um conhecimento profundo do ambiente físico, da equipe e do processo de produção (ciclo de vida do produto), auxiliando no contexto do trabalho e fornecendo insumos para construção do diagnóstico.

Os dados coletados estão apresentados a seguir.

\section{Apresentação da empresa}

A Empresa B foi fundada em 1997 e o inicio de sua atividade comercial teve um motivo bastante curioso. O negócio da família até então eram postos de combustíveis na cidade de Londrina, no entanto aceitou receber de um credor diversas calças jeans como pagamento de uma dívida de aproximadamente mil reais.

A forma escolhida para retornar aquele produto em dinheiro foi alugar um espaço no CenterShop, galeria popular na região central da cidade, e colocar 
a venda até o fim do estoque. Inicialmente o objetivo era encerrar as vendas tão rápidas acabassem as calças, mas a aceitação do produto foi grande e os empresários perceberam que aquela era uma boa oportunidade como modelo de negócio.

Com o fim dos primeiros produtos e a dificuldade em repô-los iniciouse uma produção terceirizada com faccionistas das cidades adjacentes de Londrina. Com o aquecimento da demanda foram abertas outras lojas, primeiro no Shopping Center Royal e, em seguida no elitizado Shopping Catuaí.

A princípio o planejamento do negócio estava relacionado à concepção de produzir roupas básicas com um toque de tendências da moda, a fim de suprir as necessidades de homens e mulheres de diferentes faixas etárias, além disso, a roupas seriam direcionadas ao uso diário.

A escolha da marca "Empresa B" foi conceituada com base no "modismo" de termos americanizados da época, e seu segmento buscava atingir o público masculino e feminino, todavia o foco maior direcionou-se ao público feminino, responsável por $80 \%$ das vendas atuais.

Com as variáveis ambientais favoráveis o maquinário necessário foi alugado, algumas costureiras contratadas e a Empresa B passou a ter sua produção internamente, terceirizando apenas o beneficiamento.

O crescimento não parou, hoje conta com cinco pontos de varejo situados em pontos estratégicos como avenidas e shoppigns, um adequado parque fabril com capacidade diária acima de 200 peças, incluindo seu mix que também fora expandido para produtos em malharia e tecido plano. Toda essa estrutura recebe o respaldo de aproximadamente 50 colaboradores, entre o chão de fábrica, departamento de estilo e desenvolvimento, administrativo e lojas.

A marca possui redes sociais como facebook, twitter e site, contudo são raros os investimentos em publicidade e propaganda para conciliar a formade divulgação da marca, o motivo justificado pela administração seria o investimento do capital em tecnologia e outros aspectos dos quais acreditam ser mais favorável.

Contudo, os negócios da família têm sofrido com a crescente concorrência, fomentada a cada dia pela globalização e desenvolvimentos tecnológicos, disponibilizando uma gama de produtos de variadas qualidades e custos. O exemplo disto está na entrada de produtos chineses de custo baixo e nas compras no estrangeiro (Miami) de mercadorias de custos inferiores aos nacionais, além desses concorrentes o mercado nacional tem sido prejudicado 
pelos elevados impostos dificultando a vendas e o crescimento.

Além dos fatores externos a empresa carece de reformulação e de planejamento direcionado a algumas falhas e erros cometidos internamente, interligados a identidade da marca e/ou empresa e ao processo de produção, questões que serão trabalhadas com as metodologias de gestão do design.

O quadro abaixo apresenta os dados referentes ao diagnóstico organizacional:

Quadro 5 - Resultados obtidos através do diagnóstico da Empresa B.

\begin{tabular}{|l|l|}
\hline \multicolumn{2}{|c|}{ DIAGNÓSTICO } \\
\hline MISSÃO & $\begin{array}{l}\text { Missão voltada para o produto: } \\
\text { Fornecer jeans e produtos básicos seguinto padrões de } \\
\text { qualidade, preço adequado e valor agregado aos seus } \\
\text { consumidores. } \\
\text { Missão voltada para o negócio: } \\
\text { Oferecer opções de vestuário ao seu publico alvo, } \\
\text { satisfazendo suas necessidades diárias de conforto e } \\
\text { praticidade sem negligenciar o desejo de uma identidade } \\
\text { alinhada com as tendências de moda. }\end{array}$ \\
\hline VISÃO & $\begin{array}{l}\text { Visão voltada para o produto: } \\
\text { Desenvolver processos que estruturem o mix de produtos } \\
\text { garantindo coerência conceitual de suas coleções de } \\
\text { forma planejada e estratégica proporcionando eficácia e } \\
\text { efetividade. } \\
\text { Visão voltada para o negocio: } \\
\text { Ser reconhecida como marca de identidade básica, porem } \\
\text { com influências das tendências de moda, além de ser } \\
\text { escolhida entre os jovens da cidade de Londrina e região } \\
\text { com representante do seu estilo de vida. }\end{array}$ \\
\hline VALORES & $\begin{array}{l}\text { Prezam pela qualidade das peças e pelo "preço justo" } \\
\text { praticado; } \\
\text { Valorizam matéria-prima que garanta maior índice de } \\
\text { satisfação; } \\
\text { Incentivam o crescimento profissional dos } \\
\text { colaboradores; }\end{array}$ \\
\hline
\end{tabular}




\begin{tabular}{|c|c|}
\hline PONTOS FORTES & $\begin{array}{l}\text { - Matéria prima de qualidade; } \\
\text { - } \text { Peeling de negócio; } \\
\text { - } \text { Parque fabril interno; } \\
\text { - } \text { - Controle de qualidade; } \\
\text { - } \quad \text { Logística; } \\
\text { - Rapidez de abastecimento; } \\
\text { - } \quad \text { Presença em shopping centers; } \\
\text { - Contar com vendas no atacado quando necessári }\end{array}$ \\
\hline PONTOS FRACOS & $\begin{array}{l}\text { - } \text { - } \text { - Defita de identiência no PCP (planejamento de custo de produção } \\
\text { - desenvolvimento ao descarte); } \\
\text { - } \quad \text { Deficiência na modelagem; } \\
\text { - } \quad \text { Falta de informação sobre seus concorrentes; } \\
\text { - } \quad \text { Falta de planejamento (estratégico, tático, falta de } \\
\text { - } \quad \text { processos sistematizados, coleções, cronograma); } \\
\text { - } \quad \text { peças pilotos; } \\
\text { - Mecanização do desenvolvimento (hierarquia) - } \\
\text { - } \quad \text { Faltrutura mecanicista e patriarcal; } \\
\text { interna; } \\
\text { - Visão negativa do marketing; } \\
\text { - Falta organização na criação; }\end{array}$ \\
\hline
\end{tabular}




\begin{tabular}{|c|c|}
\hline AMEAC̣AS & 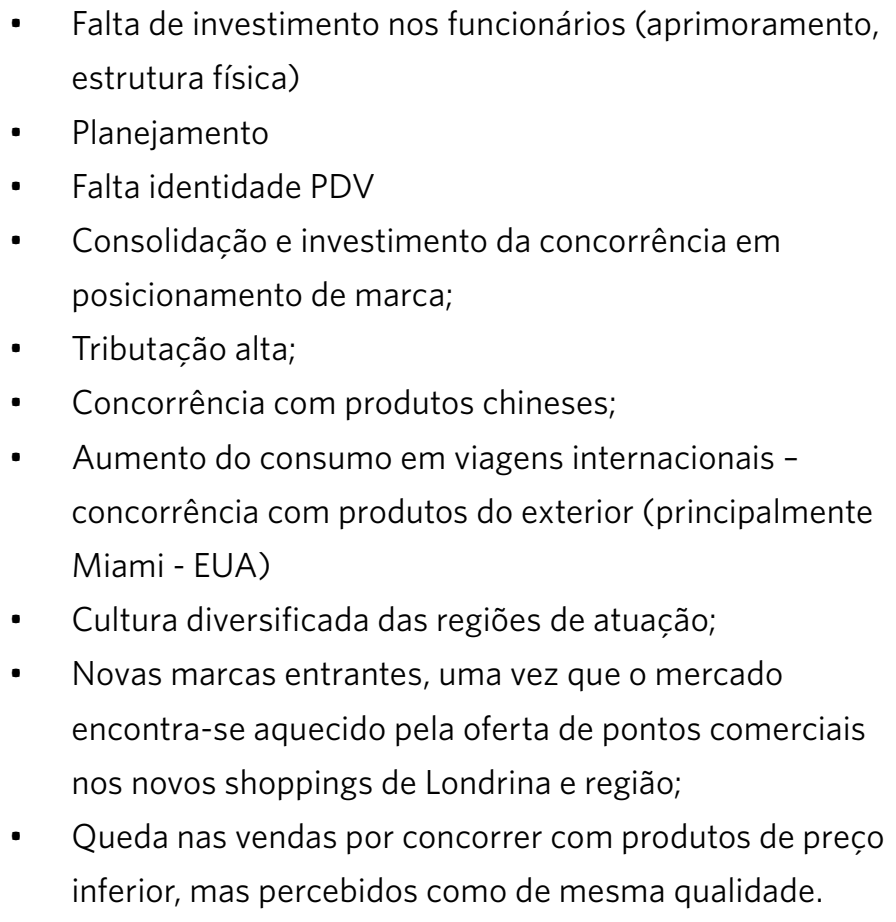 \\
\hline OPORTUNIDADES & 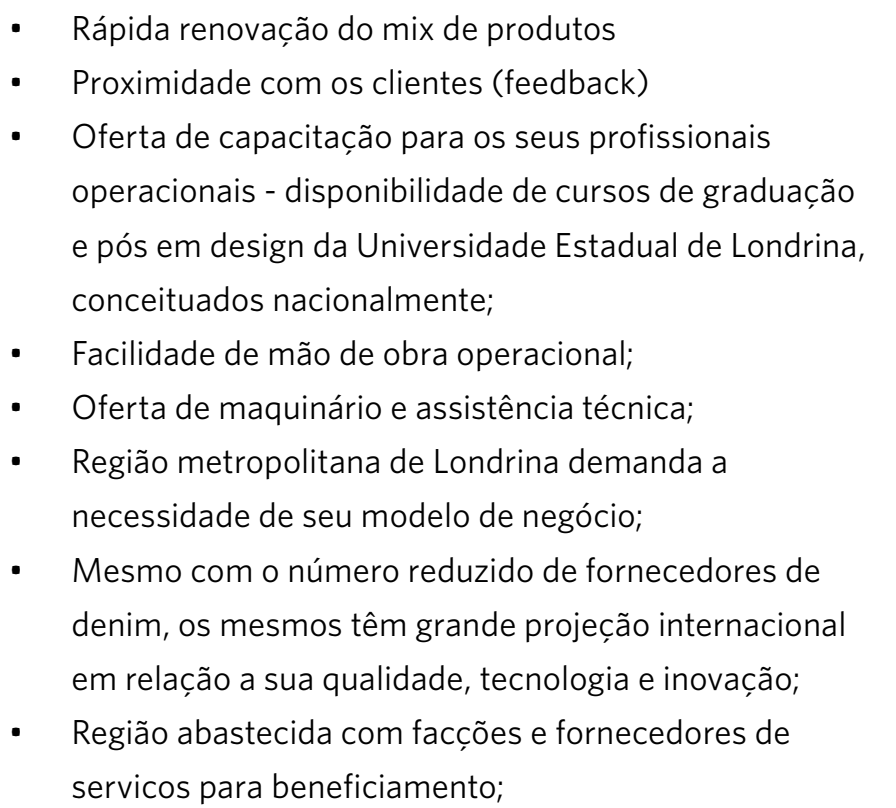 \\
\hline $\begin{array}{l}\text { CULTURA E ESTILO } \\
\text { DE GESTÃO }\end{array}$ & $\begin{array}{l}\text { - } \\
\text { - } \\
\text { - Utiliza-se da observação no PDV como forma de } \\
\text { - } \text { percepção do público consumidor } \\
\text { - Gendores utilizados como padrão de consumidor } \\
\text { - Genciamento reativo (monitoramento de reação) }\end{array}$ \\
\hline
\end{tabular}

Fonte: Os autores. 
Como já apontado anteriormente à empresa possui uma estrutura de gestão familiar, desta forma, toda a hierarquia organizacional segue o seguinte esquema:

Figura 01 - Esquema da hierarquia organizacional da Empresa B.

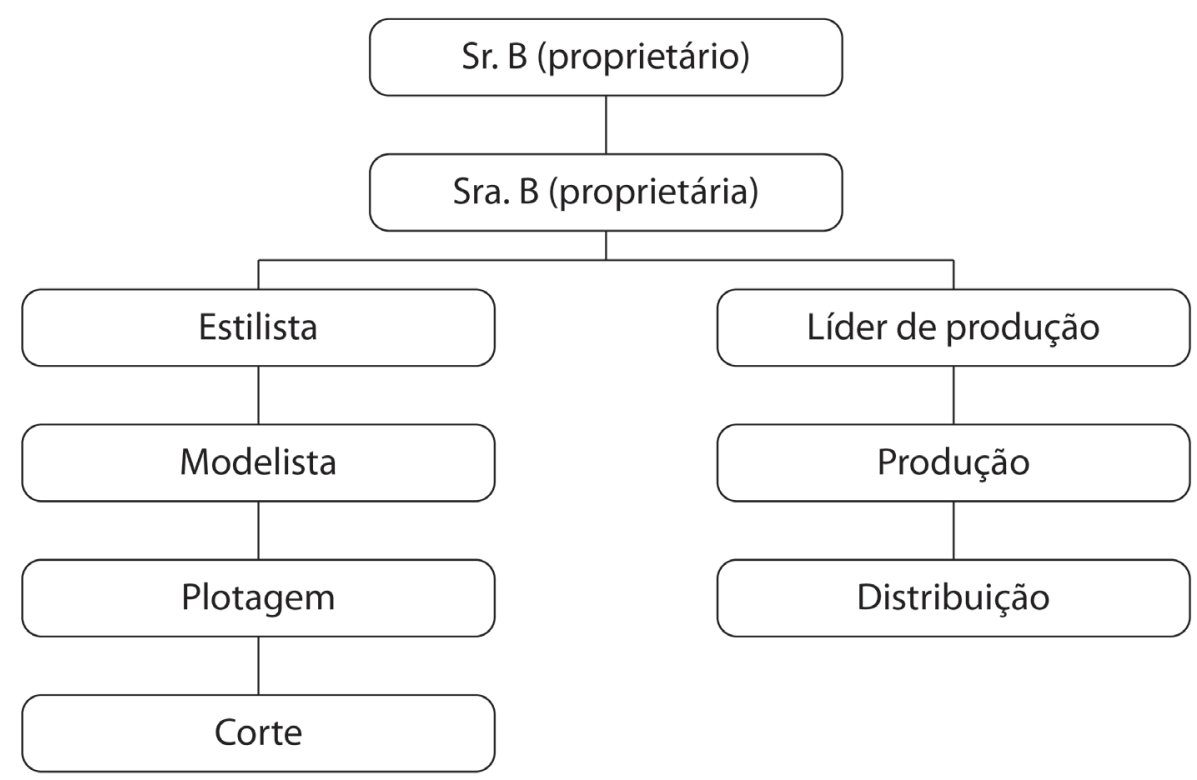

Fonte: Os autores.

O esquema organizacional confirma o domínio familiar e é esse motivo que leva a estrutura gerencial ser verticalizada, esse tipo de sistema interfere na motivação individual dos funcionários, uma vez que os membros da família são os privilegiados na empresa, a comprovação disso está no incentivo e no investimento de qualificação dos funcionários que fazem parte do núcleo familiar. Além disso, apesar de a empresa contar com uma boa estrutura física, a organização do espaço e da comunicação, principalmente no setor de criação, deixa a desejar, fatores agravados por esse sistema.

A fim de representar e avaliar melhor todo o processo de produção dos produtos nos diferentes níveis e setores realizou-se um fluxograma de ANSI, representado abaixo: 
Figura 02 - Fluxograma de ANSI estruturado através do processo da Empresa B

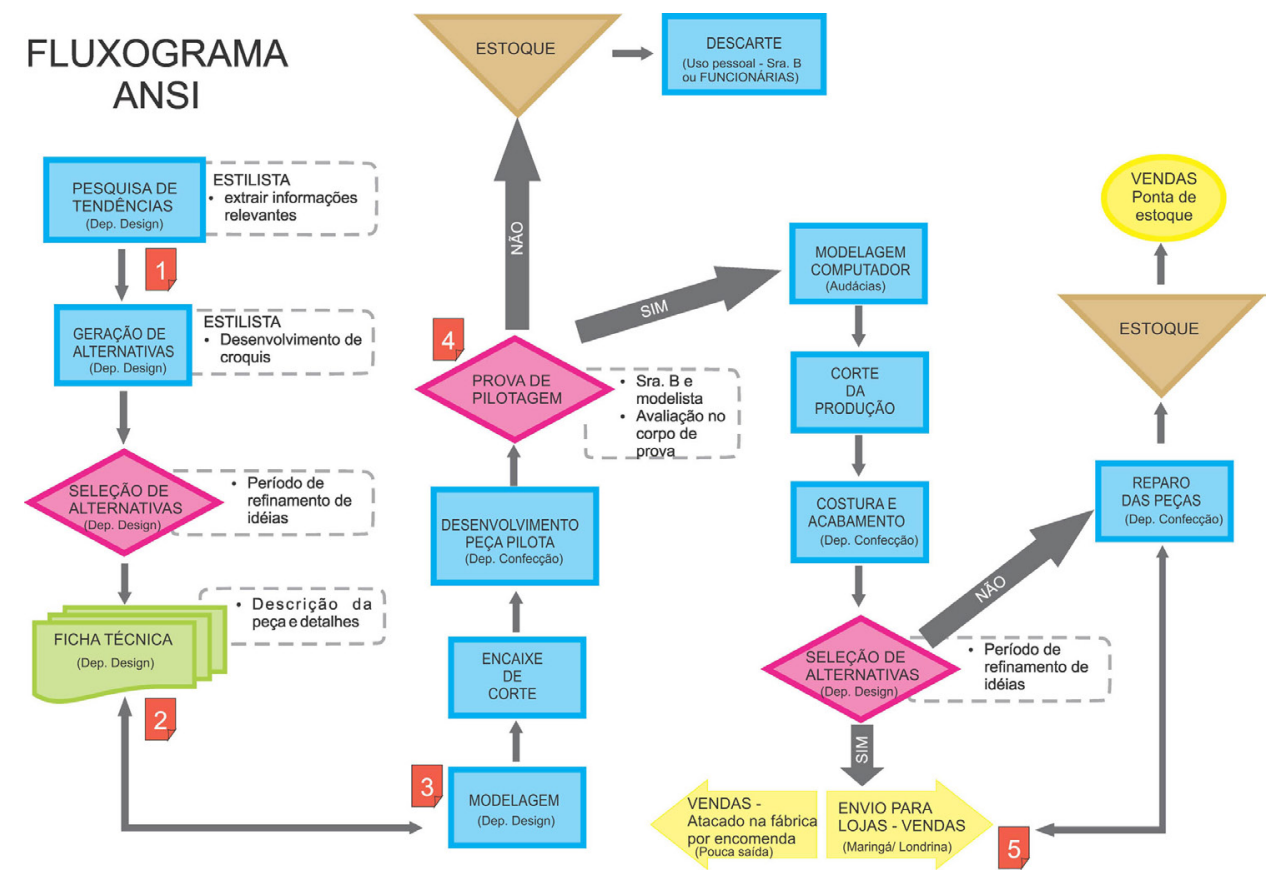

Fonte: Os autores

O fluxograma de ANSI expõe todo o processo de produção dentro da Empresa $B$, desde o início com a pesquisa de dados, passando por pontos de tomada de decisão, até a confecção e vendas do produto.

O contato do produto com o cliente está presente em duas formas, a primeira em que as peças após passar pelo teste de qualidade são encaminhadas as lojas (postos de venda) da própria marca, estando elas localizadas nas cidades de Londrina e Maringá; a segunda forma se procede através de vendas de algumas peças em estoque na forma de varejo, sob encomenda na fábrica, e posterior revenda em outras lojas.

As tarjas em vermelho representam pontos de possíveis erros, são eles:

1. Devido à ausência de um público-alvo definido a marca não extrai características de tendências diretamente ligadas a seu consumidor, mas sim, em cima de informações que possam ser trabalhadas sobre "possíveis criações" que se destinam a vender apenas, não a suprir a necessidade do usuário.

2. As falhas na ficha técnica estão na ausência de clareza de informações ou na falta de comunicação de uma mesma linguagem, ou seja, a linguagem técnica do profissional de design de moda muitas vezes não corresponde à compreensão da linguagem dos profissionais de confecção (costureiras, 
operários - chão de fábrica).

3. Um dos maiores erros da empresa B tem sido com a modelagem, já que em muitos casos por não trabalharem com um padrão não conseguem realizar a construção das peças pilotos com eficácia, assim a produção dos lotes apresentam variações de medidas dentro de uma mesma numeração. Além disso, ausência da clareza do público-alvo agrava a definição de padronização.

4. A prova de pilotagem por não ser realizadas com um perfil de modelagem coerente, auxilia nos futuros erros e falhas das peças, pois as pilotos são testadas no corpo da Sra. B e de outras funcionários, todos com aspectos diferentes.

5. A diminuição nas vendas pode ser uma conseqüência da insuficiência de divulgação e mesmo da construção da identidade de marca.

E para a representação clara da relação e atuação da Gestão do Design em diferentes níveis das organizações, planificou-se o gráfico de dimensões, readapatado e implantado tópicos de acordo com a atual situação da Empresa B.

Fihura 03 - Gráfico de dimensões da Empresa B

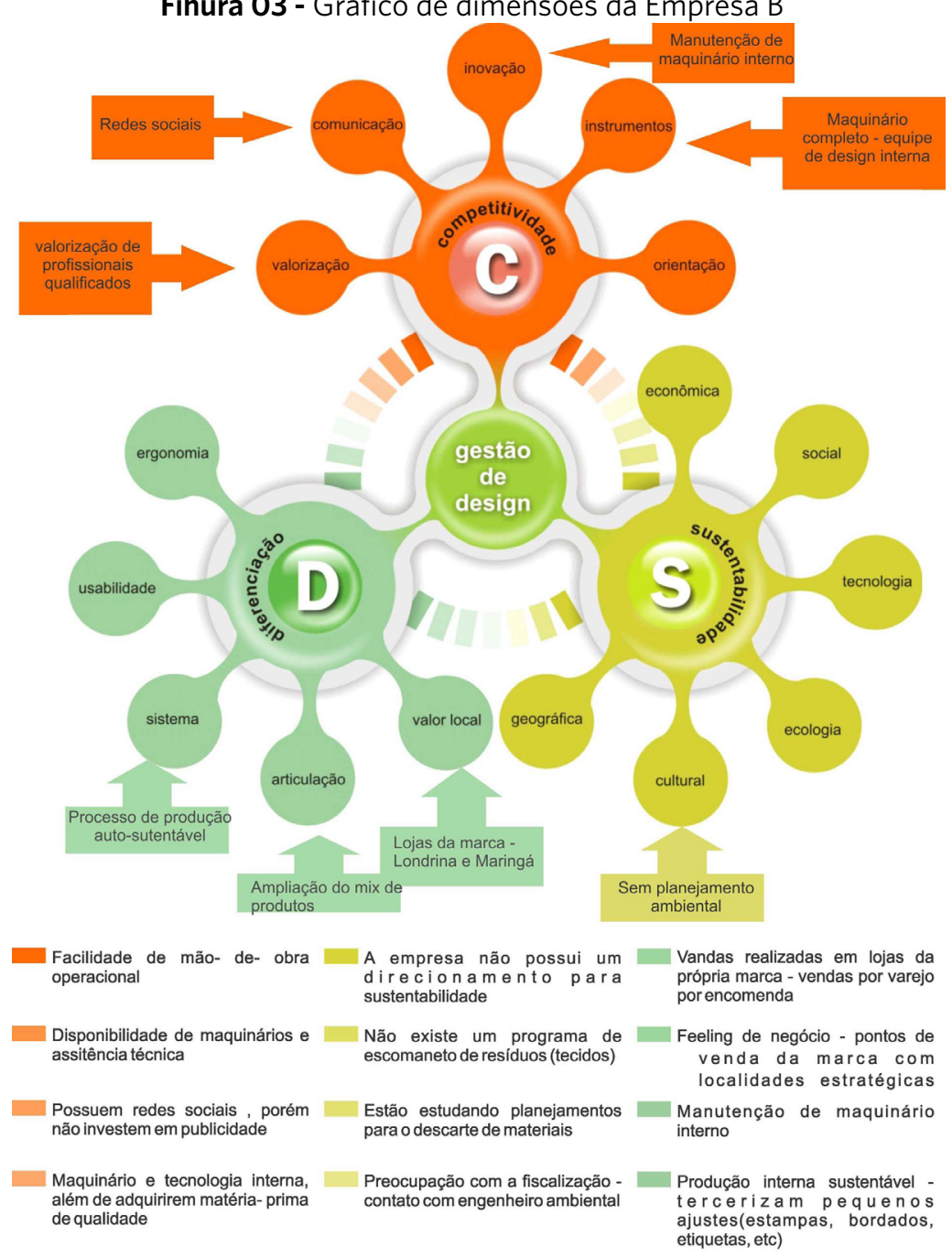

Fonte: Os autores, adaptado de Demarchi (2011). 
O exame minucioso do gráfico permite um esclarecimento dos pontos a ser trabalhado pela Gestão do Design junto a Empresa B.

\section{DISCUSSÃO DOS RESULTADOS}

O diagnóstico realizado possibilitou o conhecimento profundo e consequentemente à análise do cenário atual da empresa, com as informações obtidas foi possível detectar os agentes causadores de erros e em oposto os pontos-chaves a favor da empresa, para assim indicar os elementos e ações que contribuirão para redução, e mesmo eliminação, dos problemas identificados, além dos reforços aos aspectos favoráveis já existentes na organização.

As conjecturas a seguir sintetizam o cenário atual da Empresa B avaliada. Sua história possui consolidação há 15 anos no mercado, provida de um parque fabril consistente e postos de vendas estabelecidos em pontos comerciais favoráveis tanto na cidade de Londrina como em Maringá, o que favorece as vendas pela presente demanda e necessidade de seu modelo de negócio, além da região ser provida de facções e fornecedores de serviços para beneficiamento. No entanto, não usufrui totalmente de tais vantagens, deixando de lado o valor de marketing (realização de publicidade como estratégia de negócios), a solidificação de sua marca e identidade visual, bem como incentivos de profissionalização de seus funcionários, aspectos que devem ser planejados e postos em prática.

A Empresa B visa ambos os sexos como público, mas seu foco maior prevalece o feminino em conseqüência da alta porcentagem de vendas, esse pensamento deve ser reavaliado e aplicado ações que valorizem também o masculino, trabalhando ambos com mesma relevância, pensando sempre em oferecer produtos de qualidade e sem distinção de usuários. Contudo, não apresenta um público-alvo de discrições claras o que dificulta a padronização das peças e em conseqüência erros de produção, esses agravados pela ausência de modelos de provas coerentes.

A Gestão do Design deve então focar no marketing aperfeiçoando a comunicação da identidade visual e da marca investindo em publicidade e exposições de seus produtos no mercado diante aos concorrentes, além da reestruturação do conceito do seu público-alvo e em conjunto a padronização da modelagem das peças deixando vidente aos clientes quais os diferenciais e qualidades que a Marca B oferece.

Pensando nisso, o desejo de fornecer aos seus clientes "a roupa do diaa-dia" para trabalho, estudo entre outras ocasiões, seguindo padrões de qualidade, preços adequados e com valor agregado a marca, são questões que 
a empresa deve tomar como incentivo e meta a ser atingida, não deixando de lado a estruturação do mix de produtos com coerência conceitual das coleções. Tudo deve ser esquematizado estrategicamente, e a inovação das peças deve ser "o diferencial" presentes nos detalhes de todas as fases, processos e ações, pois é ela que atrairá o cliente e será o fator determinante na compra. Essa inovação deve ser levada em conta também na exposição e divulgação da marca diante aos concorrentes, esteja ela presente de forma explícita nos pontos de vendas, produtos de divulgação (propagandas, cartazes, folders, outdoors), e nas embalagens e acessórios (sacolas, etiquetas, tags), ou de forma implícita no conceito e imagem da marca na mente dos consumidores.

Com o diagnóstico realizado esclarecendo o perfil da empresa e tendo pleno conhecimento dos pontos fortes e fracos da empresa, inclusive seu posicionamento no mercado, a atuação da Gestão do Design em seus diferentes níveis (estratégico, tático e operacional) deve se ater em explorar as oportunidades por meio dos planejamentos concisos na tomada de decisão e, por conseguinte dar suporte a organização para a realização de ações de forma eficaz, integrativa e contínua, para assim obter o posicionamento mercadológico e o retorno desejados.

\section{CONSIDERAC̄ÕES FINAIS}

Com base no contexto abordado pelo artigo, é notória a busca do emprego e valorização de profissionais de design e com a visão da Gestão de Design como instrumentos estratégicos de competitividade, principalmente em relação à questões como inovação que é um dos elementos decisivos aos olhos do consumidor no "momento da compra".

Mediante a era tecnológica vivenciada e o contínuo aumento de mercado competitivo, que geram a cada dia inúmeras propostas de produtos aos consumidores, e aos poucos vão delineando e esculpindo seus estilos de vida e comportamento, o artigo evidenciou o elo do "atual momento" ao Design, à Gestão de Design e à Gestão Empresarial.

Nesse âmbito ficou claro como a Gestão do Design tem se destacado como um meio condutor de novas estratégias dentro das instituições. Ressaltou-se também, que a Gestão se insere nas organizações baseando-se no posicionamento adotado por cada uma, e não como um instrumento prédeterminado e facilmente implantável, pois é único a cada instituição, tomando como base o perfil diagnosticado para a realização dos planejamentos das metas e mudanças a serem realizadas, objetivando melhorias na estrutura interna e resultados positivos no posicionamento externo. Em função disso, o artigo expôs o diagnóstico da Empresa $B$, de modo a demonstrar de forma 
metódica e planificada o cenário da empresa, o que permiti aos gestores realizar planejamentos e estratégicas que devem ser inseridas e orientadas por meio da Gestão do Design.

Desta forma, para a implantação da Gestão do Design na Empresa B, é fundamental a relação dos gestores com os diferentes setores, trabalhando a importância das mudanças na cultura administrativa, principalmente no nível gerencial (topo da organização) responsável pelo comando e pela proliferação da cultura organizacional, o que o torna muitas vezes o nível mais resistente e difícil de ser modificado, e posteriormente os demais setores. Para o nível criativo, constituído da equipe de design, a gestão deve ser orientada com conhecimentos práticos adequando a equipe ao universo da Gestão do Design, permitindo uma coordenação mais independente e flexível desse setor, facilitando fluidez nas criações e tomada de decisão estratégica dos profissionais de design da própria empresa, sintonizando-os e atualizando-os as convergências dos fatos e acontecimentos mercadológicos que envolvem a empresa.

Posterior a fundamentação teórica realizada para o entendimento dos contextos abordados e a realização do diagnóstico da empresa avaliada, espera-se que a Empresa B compreenda o seu cenário atual, tanto interno como externo, e que permita, sem grande resistência, o auxílio e as conduções dos gestores de Design, realizando as mudanças necessárias em prol de um cenário almejado. 


\section{REFERÊNCIAS}

BELCHIOR, Camilo. Uma tríade para o design estratégico. Revista abcDesign, Curitiba, n. 31, p. 30, mar./maio. 2010.

CÂMARA, Jairo José; DIAS MONTEIRO, Roberta C.; ALVES OLIVEIRA, Williane; LIMA MENDONÇA, Lílian; DIAS BOTELHO, Róber. A gestão do design na concepção de novos produtos e a diferenciação metodológica. Actas de Diseño, Buenos Aires, v. 3, p. 84-87, 2007

COSTA, Isabel León Bacil. Diagnóstico da inserção de gestão de design em micro e pequenas empresas desenvolvedoras de produtos do Rio Grande do Sul através de uma análise estatística multidimensional. 2010. 187p. Dissertação (Mestrado em Design) - Universidade Federal do Rio Grande do Sul, Porto Alegre.

DELGADO, Natalia Aguilar. A inovação sob a perspectiva do Desenvolvimento Sustentável: Os casos de uma cooperativa de laticínios brasileira e de outra Francesa. 2007. 230 p. Monografia (Mestrado Administração - Gestão de Tecnologia e Produção) - Universidade Federal do Rio Grande do Sul, Porto Alegre.

DEMARCHI, Ana Paula Perfetto. Gestão estratégica de design com a abordagem de design thinking: proposta de um sistema de produção do conhecimento. 2011. 302p. Tese (Doutorado - Engenharia e Gestão do Conhecimento) - Universidade Federal De Santa Catarina, Florianópolis.

FUJITA, Carolina Taeko; BECKER, Alessandra D.; KISTMANN, Virginia

B. Competitividade e gestão do design com foco no consumidor. In: 2010 - 9o CONGRESSO BRASILEIRO DE PESQUISA E DESENVOLVIMENTO EM DESIGN, 9., 2010, São Paulo. Anais... São Paulo: P\&D Design, 2010. p. 657-667.

LOPES, Edney; AGUIAR, Flávio; JUNIOR, Glaucio; GUILHERME, João; PRADO, Warlei. Diagnóstico Organizacional. Belo Horizonte: Faculdade Novos Horizontes, 2008. Disponível em:<http://www.unihorizontes.br/ proj_inter20081/adm/empresa_beta.pdf>. Acesso em: 10 jul. 2013.

MACRI, Renato Domingues Záccaro; MARTINS, Rosane Fonseca de Freitas. A Gestão de Design em uma empresa do ramo de chocolates: proposição de ações de Gestão de Design estratégico com base em diagnóstico para consolidação da marca. Projética, Londrina, v. 1, n.1, p. 5-25, dez. 2010. 
MAGALHÃES, Claudio de Freitas. Design estratégico - Integração e ação do design industrial dentro das empresas. Rio de Janeiro: SENAI, 1997.

MANUAL de Gestão do design. Centro Português de Design. Portugal, 1997.

MARTINS, Rosane F. F.; MERINO, Eugenio Andrés D. A gestão de design como estratégia organizacional. Londrina: EDUEL, 2008.

MOZOTA, Brigitte Borja. Gestão do design: usando o design para construir valor de marca e inovação corporativa. Porto alegre: Bookman, 2011.

NETO, A.; TEIXEIRA, J. M.; MERINO, E. A. D. A contribuição da gestão de design na valorização de grupos produtivos de pequeno porte vinculados à origem. In: CONGRESSO INTERNACIONAL DE PESQUISA EM DESIGN, 9., 2009, Bauru. Anais... Bauru, 2009. p. 601-607.

NEVES, José Luis. Pesquisa qualitativa - características, usos e possibilidades. Caderno de Pesquisas em Administração, São Paulo, v. 1, n. 3, jul./dez. 1996.

ODA, Luciana Sayuri. Diagnóstico de design: definindo indicadores para mensurar a contribuição do design no desempenho empresarial de MPES. 2010. 140 p. Monografia (Mestrado Design - Gestão Estratégica de Design) - Universidade Federal De Santa Catarina, Florianópolis.

RECH, S. R. Cadeia Produtiva da Moda: um modelo conceitual de análise da competitividade no elo confecção. 2006. Tese (Programa de PósGraduação em Engenharia de Produção) - Universidade Federal de Santa Catarina, Florianópolis, 2006.

RODA, R.; KRUCKEN, L. Gestão do design aplicada ao modelo atual das organizações: agregando valor a serviços. In: CONGRESSO BRASILEIRO DE PESQUISA E DESENVOLVIMENTO EM DESIGN, 6., 2004, São Paulo. Anais... São Paulo: Fundação Armando Alvares Penteado, 2004.

SILVA, Cláudio Henrique da. Balanced scorecard como ferramenta para gestão estratégica de design. 2009. 206 p. Monografia (Mestrado Design e Expressão Gráfica) - Universidade Federal De Santa Catarina, Florianópolis.

TERENCE, A. C. F.; ESCRIVAO FILHO, E. Elaboração do planejamento 
estratégico: estudo e aplicação de um roteiro em pequenas empresas.

Revista da Micro e Pequena Empresa - RMPE, Campo Limpo Paulista, v. 1, p. 35-52, 2007. 


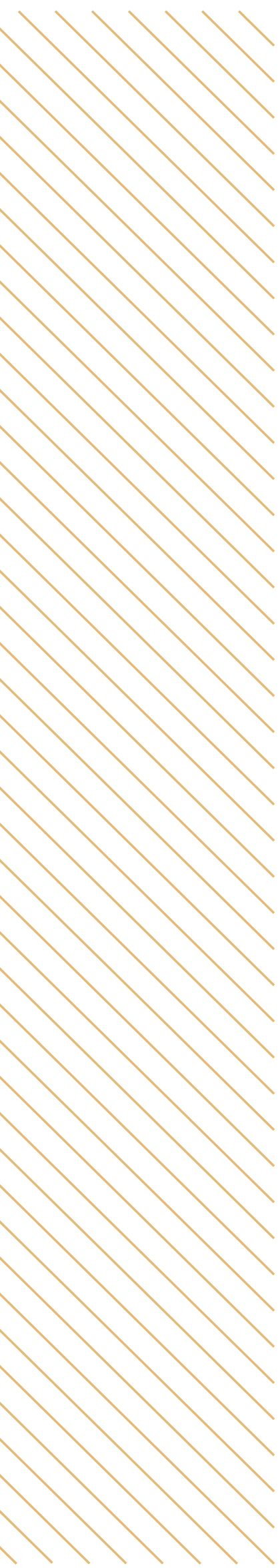

